\title{
As contribuições do PIBID para a formação continuada dos professores da Educação Básica: algumas reflexões dos professores supervisores
}

The contributions of the PIBID to the constant training of Basic Education teachers: some reflections from student teacher supervisors

Lucas dos Santos Galiza José Gilberto da Silva Mara A. Alves da Silva

Resumo: O presente artigo discute as contribuições do Programa Institucional de Bolsa de Iniciação à Docência para formação do professor supervisor do subprojeto de Química, analisando suas concepções e o aporte do programa na ação docente. Este estudo é de abordagem qualitativa, com características de pesquisa de campo, cujos dados foram obtidos por meio de questionário com questões discursivas e objetivas e discutidos segundo os pressupostos da Análise Textual Discursiva. Os sujeitos participantes deste estudo foram cinco professores supervisores das escolas do município de Amargosa, interior do Estado da Bahia, e vinculadas ao subprojeto de Química. A partir dos resultados foi observado que o PIBID proporciona ao docente a reavaliação de sua prática mediante a condução e acompanhamento dos novos educadores em formação, refletindo sobre novas aprendizagens com os licenciandos bolsistas por intermédio de estratégias didáticas diferenciadas e construídas coletivamente. Além disso, foi destacado a aproximação da Universidade com as escolas de educação básica, com a problematização e solução de conflitos em grupo. Deste modo, o professor supervisor desempenha um papel fundamental na escola campo, proporcionando mudanças no cenário escolar e na formação docente a partir da sua inserção no programa, agregando novos conhecimentos e aprendizagens, colaborando com a formação inicial dos licenciandos em Química e fortalecendo a sua própria formação.

Palavras-chave: Professor supervisor; PIBID; Formação docente.

Abstract: This article discusses the contributions of the Institutional Program of Initiation to Teaching Scholarship (PIBID) to the training of the student teacher supervisor of the Chemistry subproject, analyzing its conceptions and the contribution of the program to the teaching practice. This study is a qualitative approach, with characteristics of field research, whose data were obtained through a questionnaire with discursive and objective questions and discussed according to the assumptions of Textual Discourse Analysis. The individuals participating in this study were five student teacher supervisors from schools associated to the Chemistry subproject in the municipality of Amargosa (State of Bahia). Based on the results, it was observed that PIBID provides teachers with a reassessment of their practice by conducting and monitoring new educators in training, reflecting on new learning with scholarship holders through differentiated and collectively constructed teaching strategies. In addition, the University's approach to basic education schools was highlighted, with the problematization and solution of conflicts in group. In this way, the student teacher supervisor plays a fundamental role in the school, providing changes in the school scenario and in teacher training from the moment they are inserted in the program, 
adding new knowledge and learning, collaborating with the initial training of undergraduates in Chemistry and strengthening their training itself.

Keywords: Student teacher supervisor; PIBID; Teacher training.

\section{Introdução}

A formação de professores no Brasil tem sido um tema de muita discussão desde a década de 70 do século XX (CANDAU, 1982). Desde então, ocorreram várias discussões sobre a formação docente na educação básica, com a implantação da Lei de Diretrizes e Bases da Educação (LDB) e mais recentemente com a aprovação do Plano Nacional de Educação (PNE) "[...] composto por 10 diretrizes, 20 metas e um conjunto de 254 estratégias, aglutinou um conjunto de necessidades para a educação brasileira estipulando em alguns casos prazos para a sua concreta realização" (GATTI et al., 2019, p. 66). Dentre as políticas públicas pensadas para fortalecer a formação de professores, temos o Programa Institucional de Bolsa de Iniciação à Docência (PIBID).

O PIBID foi criado em 2007 e regulamentado pelo Decreto $N^{0} 7.219$ (BRASIL, 2010b, p.4) tendo como seguintes objetivos:

I - incentivar a formação de docentes em nível superior para a educação básica;

II - contribuir para a valorização do magistério;

III - elevar a qualidade da formação inicial de professores nos cursos de licenciatura, promovendo a integração entre educação superior e educação básica;

IV - inserir os licenciandos no cotidiano de escolas da rede pública de educação, proporcionando-Ihes oportunidades de criação e participação em experiências metodológicas, tecnológicas e práticas docentes de caráter inovador e interdisciplinar que busquem a superação de problemas identificados no processo de ensino-aprendizagem;

V - incentivar escolas públicas de educação básica, mobilizando seus professores como coformadores dos futuros docentes e tornando-as protagonistas nos processos de formação inicial para o magistério; e

VI - contribuir para a articulação entre teoria e prática necessárias à formação dos docentes, elevando a qualidade das ações acadêmicas nos cursos de licenciatura. 
A partir desses objetivos verificamos uma preocupação com alguns princípios norteadores para a formação docente. Percebemos a partir do referido decreto, um cuidado em promover uma maior aproximação do licenciando com a realidade escolar, dialogando com professores mais experientes, trocando saberes, dividindo inquietações e buscando soluções para o fortalecimento da carreira. Segundo Gatti e colaboradores (2019, p. 195), o PIBID "[...] contribuiu para fortalecer e revitalizar as licenciaturas provocando novas práticas e novas culturas no contexto dos cursos e das escolas da educação básica."

O PIBID oferece bolsa para os licenciandos (denominados pibidianos) e docentes tanto das licenciaturas (coordenadores) quanto das escolas públicas (supervisores). Os professores bolsistas das escolas públicas da educação básica, denominados supervisores, exercem suas ações para contribuir com o desenvolvimento profissional dos pibidianos e também como uma "ponte" entre as instituições de ensino superior e as escolas (BRASIL, 2013b).

Muitas pesquisas destacam a importância do PIBID para a formação inicial, sinalizando a permanência dos estudantes nas licenciaturas, reflexão crítica da prática docente, vivências na realidade escolar, ou seja, enriquece o debate sobre a formação docente (AMARAL, 2012; ROSA; MENDES; LOCATELLI, 2017; VOGEL; ABREU, 2019). Entretanto, poucos estudos dialogavam a respeito dos supervisores, com escassas investigações desenvolvidas sobre a concepção e contribuição do PIBID para a sua formação e atuação profissional (CALIL, 2014; OLIVEIRA; JUSTINA, 2017). Esse fato sinaliza uma lacuna de pesquisa e indica a importância deste artigo para somar na construção do conhecimento científico. Diante do exposto esta pesquisa se embasou na seguinte pergunta norteadora: Qual é a contribuição do PIBID para a formação do professor supervisor?

Nessa perspectiva, o objetivo deste estudo consistiu em investigar as contribuições do PIBID para a formação do professor supervisor das escolas estaduais do município de Amargosa, interior do Estado da Bahia. Também analisamos as concepções desses professores sobre a contribuição do referido programa na sua ação docente. 
Como o PIBID é um projeto que contempla muitos cursos e, devido a nossa área de formação basilar, direcionamos a discussão deste trabalho para a formação de professores de Química. Como outra opção metodológica, optamos por um recorte, e direcionamos nossas pesquisas para os docentes que pertencem aos subprojetos de Química do Centro de Formação de Professores (CFP) da Universidade Federal do Recôncavo da Bahia (UFRB), situado na cidade de Amargosa, pertencente ao Vale do Jiquiriçá no Estado da Bahia.

\section{Percurso Metodológico}

Este estudo faz parte de um projeto maior intitulado "Desenvolvimento profissional e a carreira docente brasileira: diálogos com professores da Educação Básica", com coordenação da professora Lúcia Gracia Ferreira Trindade. Em respeito às questões éticas de pesquisa com seres humanos e a legislação vigente (BRASIL, 2013a, 2016b), o referido projeto foi submetido ao Comitê de Ética em Pesquisa (CEP) da UFRB com o registro CAAE 72103517.4.0000.0056 e com aprovação consolidada por meio do parecer 2239971. Também de acordo com as referidas leis, todos os participantes desta investigação e seus locais de atuação foram codificados.

O local de desenvolvimento da pesquisa foram três escolas estaduais do município de Amargosa-BA (codificadas por CE-1, CE-2 e CE-3), parceiras em dois subprojetos de Química do PIBID vinculados ao CFP/UFRB. Este trabalho consistiu em uma pesquisa qualitativa pois "[...] considera que há uma relação dinâmica entre o mundo real e o sujeito, isto é, um vínculo indissociável entre o mundo objetivo e a subjetividade do sujeito" (PRODANOV; FREITAS, 2013, p. 71). Os sujeitos participantes desta investigação foram cinco professores supervisores do PIBID (PS-1, PS-2, PS-3, PS-4 e PS-5), que aceitaram o nosso convite em participar do projeto e atuaram nos referidos colégios no ano de 2019.

Para contemplar os objetivos propostos neste estudo elaboramos um questionário com perguntas objetivas e subjetivas (TOZONI-REIS, 2009), para traçar o perfil dos sujeitos participantes, a formação, tempo de atuação 
profissional e demais questões relacionadas às suas concepções do PIBID e das contribuições para a formação dos bolsistas. A maioria dos participantes recebeu o questionário impresso. Contudo, um supervisor (PS-3) optou pelo envio de um link para responder ao questionário de forma online. Atendendo à solicitação do sujeito, disponibilizamos o questionário via internet. Ficamos aguardando o retorno de todos os supervisores, respeitando o tempo e disponibilidade de cada um para concluir as respostas de todas as questões.

Após a conclusão de todos os questionários, as informações obtidas foram sistematizadas por meio da Análise Textual Discursiva (ATD), a partir das discussões de Moraes (2003) e Moraes e Galiazzi (2006). Como opção metodológica, as categorias surgiram do processo exaustivo de análise, as denominadas categorias emergentes (MORAES; GALIAZZI, 2006, p. 195, grifos dos autores). Diante disso, os dados foram organizados em duas categorias: 1) As contribuições do PIBID para a formação do professor supervisor; 2) A avaliação do PIBID a partir das concepções dos supervisores de Química. Antes de apresentarmos os dados ponderamos ser pertinente apresentar o perfil dos supervisores participantes deste estudo.

\section{Perfil profissional dos supervisores e a adequação com as normativas institucionais do PIBID}

Inicialmente, apresentamos as informações obtidas sobre o perfil profissional dos cinco professores supervisores (PS-1, PS-2, PS-3, PS-4 e PS5). E a partir dos dados, consideramos a necessidade de discutir sobre alguns episódios da falta de adequação dos mesmos com as normativas institucionais indicadas nas resoluções do PIBID (BRASIL, 2010a, 2016a). Primeiro, vamos apresentar algumas informações do perfil dos professores supervisores, organizadas no Quadro 1.

Quadro 1 - Perfil dos professores supervisores

\begin{tabular}{|l|l|l|l|l|l|}
\hline Supervisor & Sexo & Idade & Escola & $\begin{array}{l}\text { Tempo de } \\
\text { magistério }\end{array}$ & $\begin{array}{l}\text { Tempo de serviço } \\
\text { na instituição }\end{array}$ \\
\hline PS-1 & M & 26 & E1 & 1,5 anos & 1 ano \\
\hline PS-2 & F & 36 & E1 & 9 anos & 8 anos \\
\hline PS-3 & M & 31 & E2 & 10 anos & 1 ano \\
\hline PS-4 & M & 30 & E2 & 9 anos & 8 anos \\
\hline
\end{tabular}




\begin{tabular}{|l|l|l|l|l|l|}
\hline PS-5 & F & 47 & E3 & 26,9 anos & 16 anos \\
\hline
\end{tabular}

Fonte: Dados da pesquisa

A partir dos dados do Quadro 1, constatamos que a maioria dos participantes são do sexo masculino, e eles são os mais jovens também, pois a idade máxima foi de 31 anos. As professoras do estudo têm 36 e 47 anos de idade, respectivamente. A média do tempo de magistério dos supervisores gira em torno de 10 anos, mas há um professor iniciante com 1,5 ano e uma professora mais madura na profissão com quase 27 anos de atuação como docente. Também percebemos que a instituição na qual os participantes deste estudo atuam como professores não foi a única de sua carreira docente, pois eles possuem menos tempo de serviço na escola do que em relação ao seu tempo de magistério.

A informação do docente com 1,5 ano de atuação profissional, nos chamou a atenção, pois ao retomamos a legislação do PIBID, constatamos que a Coordenação de Aperfeiçoamento de Pessoal de Nível Superior (CAPES), por meio da portaria $n^{\circ} 46$, de 11 de abril de 2016, no seu artigo 31, parágrafo III, dispõe que o professor supervisor do PIBID para concorrer a seleção, deve "[...] possuir experiência mínima de 2 (dois) anos no magistério na educação básica" (BRASIL, 2016a, p. 11). Com essa informação verificamos que um professor atua em tempo inferior ao exigido pelo regulamento do PIBID. Talvez a diferença de apenas 6 meses foi algo desconsiderado na seleção.

As demais informações obtidas do perfil profissional dos supervisores foram organizadas no Quadro 2. A partir desse quadro sistematizamos os seguintes dados: formação, disciplinas que lecionam e tempo de supervisão no PIBID.

Quadro 2 - Perfil profissional

\begin{tabular}{|l|l|l|l|}
\hline Supervisor & Formação & $\begin{array}{l}\text { Disciplinas que leciona na } \\
\text { instituição }\end{array}$ & $\begin{array}{l}\text { Tempo de } \\
\text { supervisã } \\
\text { o }\end{array}$ \\
\hline PS-1 & $\begin{array}{l}\text { Biologia e mestre em } \\
\text { Educação em Ciências }\end{array}$ & $\begin{array}{l}\text { Química, } \\
\text { Sociologia e Práticas } \\
\text { integradas }\end{array}$ & 8 meses \\
\hline PS-2 & $\begin{array}{l}\text { Biologia e mestrando(a) } \\
\text { em Educação do campo }\end{array}$ & Biologia & 7 anos \\
\hline PS-3 & Química & Química & 10 meses \\
\hline
\end{tabular}




\begin{tabular}{|l|l|l|l|}
\hline PS-4 & Biologia & $\begin{array}{l}\text { Biologia, Ciências e } \\
\text { Ciências e Tecnologia }\end{array}$ & 2 anos \\
\hline PS-5 & $\begin{array}{l}\text { Pedagogia e Educação } \\
\text { física }\end{array}$ & Educação Física & 11 meses \\
\hline
\end{tabular}

Fonte: Dados da pesquisa

A partir dos dados do Quadro 2, verificamos que a maioria dos supervisores tem a formação em Biologia (PS-1, PS-2 e PS-4), outra tem formação em Pedagogia e Educação Física (PS-5) e apenas um docente possui formação em Química (PS-3).

Em relação a pós-graduação, um dos participantes possui titulação de Pós-Graduação Stricto Sensu, mestre em Educação em Ciências e outra com mestrado em andamento em Educação do Campo. Também verificamos que ambos atuam na mesma instituição de ensino (E1) e são graduados em Biologia.

No cruzamento dos dados, também consideramos pertinente discutir sobre a adequação desses sujeitos participantes com as normativas institucionais do PIBID. Dos cinco supervisores apenas um docente tem formação em Química, esse fato nos inquietou e, a partir disso, investigamos as normativas institucionais. De acordo com a portaria vigente na época da seleção desses professores verificamos as seguintes indicações no seu artigo 6, parágrafo $5^{\circ}$ : "As atribuições e os requisitos do professor coordenador institucional e de área bem como as do professor supervisor e dos bolsistas serão definidos em edital, segundo as normas da CAPES" (BRASIL, 2010a, p. 27, grifos nossos). Ao analisar o edital 2018.2 de seleção PIBID $^{1}$ como requisito para a inscrição na vaga de supervisor havia algumas exigências dentre elas destacamos: "Ser professor em algumas das escolas indicadas no item 2 deste edital e atuar em sala de aula em componente curricular ou na etapa correspondente à habilitação concedida pelo curso participante do núcleo/subprojeto". Diante dessa redação, entendemos que podem se inscrever como supervisor pessoas habilitadas em Química e/ou que lecionam a disciplina de Química na escola.

Como destacamos anteriormente apenas um supervisor (PS-3) era formado em Química. Em relação as disciplinas ministradas, apenas dois

\footnotetext{
1 O referido edital foi retirado da página do CFP/UFRB.
} 
lecionavam a disciplina Química (PS-1 e PS-3). E apesar das discordâncias com as normativas do PIBID, três professores (PS-2, PS-4 e PS-5) atuaram como supervisores do subprojeto de Química do CFP/UFRB. Para entender essa situação acreditamos ser necessário promover outras investigações voltadas para as instituições e profissionais envolvidos na seleção e condução do PIBID para entendermos os limites e potencialidades de suas ações para a valorização e fortalecimento da formação inicial de professores de Química. Contudo, isso não consiste no foco deste estudo.

Além dessa discrepância com a legislação ponderamos ser preocupante ter supervisores com formação diferente e ainda que não lecionam Química na escola e mesmo assim atuarem como supervisores do subprojeto de Química do PIBID. Não podemos nos isentar do debate e de pontuar reflexões a esse respeito. Ainda mais, percebemos a partir dos dados que uma supervisora (PS2) formada em Biologia atuou por 7 anos como supervisora do PIBID no subprojeto de Química, ou seja, foi supervisora sem a formação mínima exigida.

É muito preocupante um profissional não possuir a formação específica e mesmo assim atuar como professores em aulas de Química elou ainda supervisionarem professores em formação de um subprojeto de iniciação à docência. O Censo Escolar 2017 demonstrou que 38,7\% dos docentes que atuam nas aulas de Química possuem a formação inadequada à sua atuação profissional (BRASIL, 2018). Já o Censo Escolar 2018 ponderou sobre a inadequação da formação dos professores no Brasil, indicando a existência de dados muito heterogêneos que variam de acordo com a região e complementou: "[...] No ensino médio os menores percentuais de formação adequada foram observados para os estados da Bahia e Mato Grosso, enquanto que o Distrito Federal, o Paraná e o Amapá, se destacam positivamente [...]" (BRASIL, 2019, p. 5). Ou seja, a Bahia é um dos estados brasileiros com maior quantidade de professores sem a formação adequada para a sua área de atuação. $E$ isso foi refletido pela formação dos supervisores do PIBID. É necessário o desenvolvimento de pesquisas na região para entender os motivos dessa situação. 
Além disso, é preciso alertar sobre as consequências incomensuráveis para a formação docente. Como um profissional não habilitado poderia acompanhar o bolsista em atividades para a sua iniciação em docência, se o próprio supervisor não tem a formação específica? Como dialogar sobre as estratégias didáticas no ensino de Química, se a referida disciplina não faz parte da atuação profissional do supervisor? Como a qualidade da formação docente pode ser fortalecida sem a participação de profissionais qualificados? Essas inquietações sinalizam a nossa preocupação com a importância da formação adequada, pois a entendemos como algo fundamental para a atuação profissional e para a reflexão crítica sobre os saberes necessários à docência.

Como último dado perguntamos aos supervisores se antes do PIBID, já tinham atendido licenciandos mesmo em outras instituições na função de supervisor(a) de estágio. Apenas uma supervisora não possuía essa experiência (PS-5), o que foi inquietante pois era a participante com mais tempo de atuação como professora (quase 27 anos). Todos os demais supervisores afirmaram já terem recebido estagiário em suas aulas.

Para os sujeitos que sinalizaram positivamente a indagação anterior, perguntamos se eles teriam percebido alguma diferença entre a supervisão do PIBID e do estágio. As respostas foram organizadas no Quadro 3.

Quadro 3 - Diferenças entre a supervisão do PIBID e do estágio na visão dos participantes

\begin{tabular}{|l|l|}
\hline Supervisores & Respostas \\
\hline PS-1 & $\begin{array}{l}\text { A principal diferença é o tempo de vínculo com a instituição, assim, } \\
\text { dando tempo de se fazer um trabalho mais elaborado. }\end{array}$ \\
\hline PS-2 & $\begin{array}{l}\text { O tempo conjunto para planejamento didático - pedagógico é maior } \\
\text { no PIBID. Nesse programa diagnosticamos e enfrentamos } \\
\text { demandas só percebidas como tais devido ao trabalho mais perene } \\
\text { e intenso entre supervisor e bolsistas. Isso não ocorre dessa } \\
\text { maneira no estágio. }\end{array}$ \\
\hline PS-3 & $\begin{array}{l}\text { São momentos e ações diferentes, no entanto existe uma } \\
\text { aproximação muito maior dos participantes do PIBID (bolsistas, } \\
\text { supervisores e coordenadores) com a escola. }\end{array}$ \\
\hline PS-4 & $\begin{array}{l}\text { A construção das atividades era mais elaboradas no PIBID, além } \\
\text { da proposta de discutir e avaliar cada processo junto com os } \\
\text { bolsistas. }\end{array}$ \\
\hline
\end{tabular}

Fonte: Dados da pesquisa 
A partir dos dados do Quadro 3, verificamos, a partir das respostas dos supervisores, que o tempo de acompanhamento do PIBID na escola é maior do que no estágio (PS-1 e PS-2). Esse fato aumenta o vínculo do bolsista com o supervisor e a escola (PS-1 e PS-3). Além disso, com um período maior é possível que o futuro professor possa desenvolver atividades mais elaboradas (PS-1 e PS-4), com mais tempo de planejamento (PS-2), avaliando o processo de forma mais intensa (PS-4), diagnosticando e enfrentando os desafios da vivência escolar (PS-2). Percebemos a partir dessas colocações a importância do PIBID para o fortalecimento das relações com a escola pública e a importância para a formação docente.

\section{As contribuições do PIBID para a formação do professor supervisor}

O PIBID muito tem contribuído para a formação dos Bolsistas da Licenciatura (FLECK; SANTOS, 2016), mas qual respaldo o programa tem dado ao professor da educação básica? Tem de fato contribuído para o desenvolvimento desses profissionais? Após a entrada houve algum tipo de modificação na forma de interagir em sala de aula? Estes e outros questionamentos serão discutidos ao longo desta categoria.

Indagamos aos participantes se ocorreram alterações em sua forma de atuar e/ou avaliar após o PIBID. Todos os professores supervisores sinalizaram que houve alguma mudança de sua postura em relação ao trabalho e aos discentes em sala de aula após sua entrada no programa. Entretanto, o que modificou de uma resposta para outra foi referente ao tipo de mudança, ou seja, aproximadamente $80 \%$ relataram que de fato houve uma modificação e $20 \%$ acredita que essa alteração foi parcial. Para entendermos essas colocações na sequência do questionamento, solicitamos aos professores supervisores que nos indicassem quais foram os tipos de modificações ocorridos em sala de aula. Os dados foram organizados no Quadro 4.

Quadro 4 - Alteração na prática docente devido ao PIBID

\begin{tabular}{|l|l|}
\hline Supervisores & Respostas \\
\hline PS-1 & $\begin{array}{l}\text { Desenvolvi mais um pouco da minha capacidade de trabalhar em } \\
\text { equipe, de mediar conflitos em sala de aula, tendo mais empatia, }\end{array}$ \\
\hline
\end{tabular}




\begin{tabular}{|l|l|}
\hline & senso crítico e espírito de liderança. \\
\hline PS-2 & $\begin{array}{l}\text { A partir das discussões, leitura e discussão de artigos surgiram } \\
\text { muitas reflexões da nossa prática. }\end{array}$ \\
\hline PS-3 & $\begin{array}{l}\text { Fui bolsista do PIBID durante a graduação e hoje sou supervisor, } \\
\text { são momentos é funções diferentes, mas que nos atualizamos e } \\
\text { buscamos modificar sempre para melhor o fazer pedagógico. }\end{array}$ \\
\hline PS-4 & $\begin{array}{l}\text { Não apenas por conta de sua entrada. Acredito que ao longo de } \\
\text { sua carreira profissional o professor deve sempre atualizar-se, } \\
\text { agregando novas ideias e novas metodologias na busca de atender } \\
\text { de forma positiva o desenvolvimento do conhecimento de seus } \\
\text { alunos. }\end{array}$ \\
\hline PS-5 & $\begin{array}{l}\text { Houve contribuição para dinamizar as avaliações, mas não } \\
\text { alteração. }\end{array}$ \\
\hline
\end{tabular}

Fonte: Dados da pesquisa

Na percepção dos professores envolvidos na investigação ao longo de sua formação vão se aperfeiçoando, modificando sua conduta profissional e agregando novas ideias e metodologias. Segundo Freire (1996, p. 39) "[...] hoje ou de ontem que se pode melhorar a próxima prática", deste modo, o professor deve estar disposto a melhorar a cada ação. A partir das respostas do Quadro 4 , verificamos que o programa tem propiciado aos supervisores se reavaliarem enquanto integrantes do processo formativo dos pibidianos, criando novas possibilidades e reflexões da carreira docente. Apenas PS-5 sinalizou que não alterou a sua atuação, mas que contribuiu para dinamizar as suas avaliações, o que, de certo modo, podemos considerar como algum tipo de mudança na sua prática avaliativa.

Para aprofundarmos o entendimento das contribuições do PIBID para a formação do professor supervisor, indagamos aos sujeitos participantes desta pesquisa: Qual é a contribuição que o PIBID proporciona no seu trabalho docente? Os dados foram sistematizados no Quadro 5.

Quadro 5 - Contribuições do PIBID para o trabalho docente

\begin{tabular}{|l|l|}
\hline Supervisores & Contribuições \\
\hline PS-1 & $\begin{array}{l}\text { Contribuir para a seleção de encaminhamento de demandas escolares ainda } \\
\text { não vistas como tais por nós professores; } \\
\text { Traçar possíveis caminhos que buscam soluções para os problemas } \\
\text { encontrados na escola; } \\
\text { Meu desenvolvimento enquanto professor um olhar mais sensível a } \\
\text { trabalhar com os conflitos que surgem em sala de aula no sentido de mediar } \\
\text { esses conflitos e contribuir para encaminhá-los, ou seja, superar as } \\
\text { contradições existentes na escola; }\end{array}$ \\
\hline PS-2 & $\begin{array}{l}\text { A troca de informações e de ideias com os participantes do PIBID; } \\
\text { P amadurecimento de novas ideias que por muitas vezes ficam só no papel; } \\
\text { Traz uma nova percepção de carreira docente, já que os trabalhos são }\end{array}$ \\
\hline
\end{tabular}




\begin{tabular}{|l|l|}
\hline & feitos, na maioria das vezes em grupo, somando ideias de formação; \\
\hline PS-4 & $\begin{array}{l}\text { Repensar e avaliar a minha prática a partir das discussões; } \\
\text { Construção de intervenções que realizamos em grupo no PIBID; }\end{array}$ \\
\hline PS-5 & $\begin{array}{l}\text { Maior conhecimento unindo a teoria e a prática; } \\
\text { Maior aprendizado do docente; } \\
\text { Capacitando os alunos na formação profissional; }\end{array}$ \\
\hline
\end{tabular}

Fonte: Dados da pesquisa

A partir das respostas dos supervisores percebemos que o PIBID contribuiu com o trabalho docente por meio de vivências e aprendizagens junto aos bolsistas, possibilitando ao professor supervisor em repensar e avaliar sua prática como educador. Assim como Vogel e Abreu (2019, p. 20) comentaram que "[...] o PIBID, em sua relevante dinâmica, [...], atua como caminho para ressignificação do processo de formação docente".

O trabalho coletivo foi o ponto mais sinalizado nas respostas (PS-2, PS3 e PS-4), que possibilitou a construção de intervenções para suprir as demandas escolares. E esse fato oportuniza uma maior articulação entre Teoria e Prática (PS-5), fortalecendo o aprendizado de todos os envolvidos pela troca de informações e ideias (PS-2 e PS-3). O desenvolvimento de um olhar mais sensível (PS-1) para a mediação de conflitos na escola foi outra sinalização importante, pois assim como o supervisor contribui para a formação profissional dos pibidianos (PS-5), a estrutura do programa também proporciona uma formação continuada para esse supervisor. Assim, entendemos que o programa também se consolida na proposta de formação continuada, como destacou Rosa e Mattos (2013, p. 165):

[...] por ser um programa que proporciona movimento e desenvolvimento da cultura escolar, além de trazer contribuições para a articulação entre teoria e prática necessárias ao desenvolvimento profissional dos docentes, está somando outras possibilidades no que se refere à formação de professores, caracterizando-se, também, como um programa que pode trazer melhorias para o exercício profissional dos professores da Educação Básica.

Perguntamos aos supervisores se usariam as intervenções construídas com os bolsistas do subprojeto de Química em suas aulas ao decorrer dos anos. As respostas foram organizadas no Quadro 6. 
Quadro 6 - Uso das intervenções construídas coletivamente no PIBID

\begin{tabular}{|l|l|}
\hline Supervisores & Respostas \\
\hline PS-1 & $\begin{array}{l}\text { Sem dúvida alguma, um material muito bem feito e inovador foi } \\
\text { deixado pelo grupo - a tabela periódica montável. }\end{array}$ \\
\hline PS-2 & $\begin{array}{l}\text { Claro que sim, São formas lúdicas, interessantes que estimulam a } \\
\text { curiosidade e o desenvolvimento dos nossos estudantes para o } \\
\text { ensino de Química. }\end{array}$ \\
\hline PS-3 & $\begin{array}{l}\text { Usaria e uso essas intervenções, foram ações positivas que } \\
\text { geraram bons frutos. }\end{array}$ \\
\hline PS-4 & $\begin{array}{l}\text { Sim! Considero toda forma de ensino como válida, assim novas } \\
\text { ideias devem fazer parte da rotina profissional do docente. Com } \\
\text { isso, as intervenções realizadas pelos pibidianos, sendo ela válida } \\
\text { para o desenvolvimento do conhecimento, devem sim ser usadas e } \\
\text { reusadas em nossas aulas. }\end{array}$ \\
\hline PS-5 & $\begin{array}{l}\text { Sim, pois as aulas focam na teoria e prática educacional } \\
\text { contribuindo para um trabalho já realizado no Centro. }\end{array}$ \\
\hline
\end{tabular}

Fonte: Dados da pesquisa

Todos os sujeitos participantes deste estudo afirmaram que utilizariam as intervenções construídas em suas aulas. Além disso, destacaram a importância na confecção de atividades diferenciadas (PS-1, PS-2 e PS-4), que estimulam a curiosidade de seus alunos (PS-2), gerando bons resultados de aprendizagem dos conteúdos químicos (PS-2 e PS-3), articulando a teoria com a prática (PS-5). Diante dessas colocações citamos Rosa, Mendes e Locatelli (2017, p. 5):

Essa demanda potencialmente promove vínculo entre formação específica e formação pedagógica dos licenciandos, mas também da percepção do professor supervisor da necessidade de aprimorar as opções teóricas metodológicas dos bolsistas PIBID, disponibilizando a esses subsídios que venham contribuir com sua futura prática educativa.

Concordamos com os referidos autores, pois a partir das respostas dos supervisores (Quadro 6), percebemos que essas ações proporcionam a mobilização de saberes docentes fortalecendo tanto a formação específica quanto a pedagógica dos pibidianos e dos superiores. E muitas das atividades construídas ainda são utilizadas pelo professor, como destacado por PS-1 ao relatar sobre a Tabela Periódica Móvel deixada para a escola e o professor no intuito de facilitar o ensino do assunto.

Com isso, podemos observar as contribuições do programa tanto para a escola, propondo novas estratégias de ensino, quanto para a formação do 
professor supervisor, na questão de dialogar com os seus pares sobre a dinâmica do cotidiano escolar.

\section{A avaliação do PIBID a partir das concepções dos supervisores de Química}

Neste trabalho consideramos ser muito importante ouvir o posicionamento dos supervisores sobre a forma como o PIBID vem sendo trabalhado nas escolas parceiras. É importante darmos voz também para os professores da educação básica para entendermos os limites e potencialidades desse programa no ambiente escolar.

Os professores foram indagados para avaliarem como o PIBID é trabalhado nas escolas. Adiante, no Quadro 7 foram demonstradas as explicações referentes a esse questionamento.

Quadro 7 - Avaliação dos supervisores sobre a forma de trabalho do PIBID nas escolas

\begin{tabular}{|l|l|}
\hline Supervisores & Respostas \\
\hline PS-1 & $\begin{array}{l}\text { Muitas vezes esse trabalho é insuficiente; } \\
\text { Em alguns momentos é plenamente satisfatório; } \\
\text { Algo que a meu ver ajudaria muito seria tornar a prática de orientação } \\
\text { teórico-metodológica mais frequente na vida dos pibidianos; } \\
\text { Muitas vezes essa formação que ocorre nas Universidades é de deficiente } \\
\text { e não possibilita a vinculação entre teoria e prática; }\end{array}$ \\
\hline PS-2 & $\begin{array}{l}\text { Ainda vejo a necessidade de uma maior participação do PIBID no dia-a- } \\
\text { dia da escola. }\end{array}$ \\
\hline PS-3 & $\begin{array}{l}\text { Acho que segue sempre o edital; } \\
\text { PS-4 programa acaba proporcionando aprendizagem da docência na } \\
\text { formação inicial, sendo esse seu objetivo; }\end{array}$ \\
\hline PS-5 & $\begin{array}{l}\text { A distância do CFP da escola e os horários era algo que dificultava a } \\
\text { presença de todos os alunos nas atividades desenvolvidas. }\end{array}$ \\
\hline
\end{tabular}

Fonte: Dados da pesquisa

De acordo com as respostas dos participantes foram sinalizados limites e potencialidades do trabalho realizado pelo PIBID. Como pontos fortes destacamos a possibilidade dos pibidianos aprenderem a profissão docente de acordo com o que é estabelecido institucionalmente pelas normativas do programa (PS-3, PS-4). Como aspectos a serem melhorados os supervisores sinalizaram alguns problemas: mais momentos de orientação teóricometodológica para suprir as lacunas da formação inicial na graduação, buscando uma melhor articulação entre teoria e prática (PS-1); a necessidade 
de maior participação dos pibidianos no cotidiano escolar (PS-2); distanciamento geográfico entre a universidade e escola, com incompatibilidade de horários, o que refletia na dificuldade de participação de todos os pibidianos nas ações escolares (PS-5).

Esses limites pontuados pelos participantes deste estudo são importantes. Torna-se essencial um "[...] olhar crítico-reflexivo perante à realidade educacional rumo a um processo de crescimento pessoal e profissional, possibilitando novas formas de aprender, apreender, atuar, solucionar problemas, discutir, enfrentar conflitos" (VOGEL, ABREU, 2019, p. 22, grifos nossos). Essas críticas pontuadas pelos supervisores são pertinentes para lapidar as ações futuras dos subprojetos na escola. Por isso, foram apresentadas nesta pesquisa como uma possibilidade de proporcionar a reflexão e diálogo para a sua superação.

Depois de avaliarem as formas do trabalho desenvolvido nos subprojetos de Química, solicitamos aos supervisores para analisarem a contribuição do PIBID para as escolas parceiras. Os dados são apresentados no Quadro 8.

Quadro 8 - Contribuições do PIBID para as escolas parceiras

\begin{tabular}{|l|l|}
\hline Supervisores & Respostas \\
\hline PS-1 & $\begin{array}{l}\text { Ainda têm ficado muito restritas a escola para a qual os estudantes foram } \\
\text { direcionados; } \\
\text { O trabalho poderia ser potencializado a partir de um olhar mais preciso } \\
\text { para os temas controversos e socialmente relevantes que marcam a } \\
\text { contemporaneidade; }\end{array}$ \\
\hline PS-2 & $\begin{array}{l}\text { Colaborar no desenvolvimento de aulas que melhorem a compreensão } \\
\text { dos alunos em conteúdo que apresentam dificuldades; } \\
\text { Tem estimulado os nossos alunos a seguirem um curso em nivel superior } \\
\text { pois gostam desse convívio com os bolsistas/Alunos da Universidade; }\end{array}$ \\
\hline PS-3 & $\begin{array}{l}\text { Engrandecedor, possibilita uma aproximação da Universidade com as } \\
\text { escolas; }\end{array}$ \\
\hline PS-4 & $\begin{array}{l}\text { Avalio como boa, pois traz novas relações profissionais, novas ideias e } \\
\text { contribui na construção de novos saberes. }\end{array}$ \\
\hline PS-5 & $\begin{array}{l}\text { Possibilita com que os alunos tenham oficinas oferecidas pelos pibidianos; } \\
\text { Experiência nova e professores/alunos com dinâmicas novas e } \\
\text { conhecimentos diferentes. }\end{array}$ \\
\hline
\end{tabular}

Fonte: Dados da pesquisa

A partir do quadro 8, vislumbrados diversas contribuições do PIBID para as escolas parceiras. Os participantes PS-2 e PS-4, relataram que os benefícios à escola são direcionados aos discentes que nela estuda, proporcionando uma aproximação com os pibidianos, estimulando os 
estudantes a ingressarem no Ensino Superior e a construção de novas relações profissionais. Para PS-4 e PS-5 oportuniza despertar novos conhecimentos por meio de abordagens produtivas como a construção de novos saberes e vivências com dinâmicas novas para a construção do conhecimento químico. Já PS-3 destacou a aproximação entre a escola e a universidade. Essa indicação também foi pontuada por Calil (2014, p. 13) ao destacar que "[...] o PIBID aproxima a universidade e a escola e cria uma inovação no processo de formação de professores".

Apesar dos apontamentos positivos da maioria dos sujeitos, PS-1 destacou alguns limites sobre a restrição de ação dos subprojetos do PIBID somente às escolas parceiras e a necessidade de discussões socialmente relevantes atrelada aos conteúdos químicos. Realmente os subprojetos só atuam nas escolas parceiras devido a convênios firmados por meio dos editais do PIBID. Contudo, entendemos a importância desse programa e a necessidade de expansão da sua atuação para mais espaços escolares. Em relação às questões sociais, entendemos a importância e relevância de abordar os conteúdos químicos promovendo a reflexão dos estudantes sobre aspectos sociais da sua realidade.

Em outro questionamento pedimos aos supervisores para sinalizar algumas melhorias necessárias para aprimorar os subprojetos de Química do PIBID. Essas contribuições são apresentadas no Quadro 9.

Quadro 9 - Algumas melhorias necessárias para os subprojetos de Química do PIBID

\begin{tabular}{|l|l|}
\hline Supervisores & Respostas \\
\hline PS-1 & $\begin{array}{l}\text { Quando trabalhei com um grupo de pibidianos percebi muitas carências } \\
\text { formativas e afetivas nos bolsistas; } \\
\text { Poderia trabalhar a questão das relações interpessoais e as } \\
\text { subjetividades dos estudantes. }\end{array}$ \\
\hline PS-2 & $\begin{array}{l}\text { Discussões sobre empatia, relação interpessoais com o grupo, estes que } \\
\text { são habilidades fundamentais para a convivência em grupo que tem se } \\
\text { tornado cada vez mais necessário no ambiente escolar. }\end{array}$ \\
\hline PS-3 & $\begin{array}{l}\text { Penso que os editais deveriam também ser discutidos com as escolas, } \\
\text { para que suas necessidades e especificidades sejam atendidas também. }\end{array}$ \\
\hline PS-4 & $\begin{array}{l}\text { Sinto falta de uma maior participação do supervisor como professor } \\
\text { colaborador das ações, pois acredito que poderia trazer uma relação mais } \\
\text { segura dos pibidianos com o programa. }\end{array}$ \\
\hline PS-5 & O dinamismo e a atualização constante dos saberes. \\
\hline
\end{tabular}

Fonte: Dados da pesquisa 
Os supervisores PS-1 e PS-2 trouxeram como contribuição a necessidade de discutir sobre as relações interpessoais e afetivas com os bolsistas, percebido por um supervisor (PS-1) como uma carência de muitos bolsistas. Esse fato é muito importante e destacado por outros pesquisadores, no qual destacamos a citação de Calil (2014, p. 12):

As ações de acompanhamento dos licenciandos exigem dos professores supervisores empenho, estudo, revisão das próprias práticas pedagógicas que, como já citado, implicam também compromisso moral e responsabilidade sobre o sujeito aprendente, revelados num espaço crescente de trocas que não são limitadas apenas pelo aspecto pedagógico, mas também pelo afetivo.

Assim como a referida autora, entendemos que a formação docente também engloba as questões humanas. A construção de um profissional não se baseia somente em uma perspectiva técnica, há a necessidade de dialogar e fortalecer as relações interpessoais, cuidar da subjetividade do sujeito e refletir sobre as complexidades envolvidas nos sentimentos de frustação, raiva, emoção, angústia, empatia etc.

Outra contribuição foi a inclusão das escolas parcerias na construção dos editais do PIBID (PS-3). Realmente é uma indicação importante, pois a parceria institucional também precisa ser estreitada por meio dos documentos e editais de seleção. É necessário reconhecer os anseios dentro do contexto escolar, por isso consideramos importante a participação efetiva das escolas na elaboração dos editais, pois serão capazes de sinalizar as suas necessidades e proporcionar direcionamentos mais efetivos para a consolidação dos subprojetos. E isso acaba refletindo também na indicação de PS-4, ao sinalizar a necessidade de uma aproximação maior do coordenador do subprojeto com o chão da sala de aula.

O dinamismo e a atualização constante dos saberes relatados pela supervisora PS-5, são algo muito importante para a formação docente tanto dos pibidianos quanto para os supervisores. Concordamos com Rosa, Mendes e Locatelli (2017, p. 98) ao mencionarem sobre a complexidade do processo formativo docente: 
A formação docente é um complexo processo que envolve, além da formação acadêmica, os saberes advindos das interfaces que se estabelecem entre sujeito social e sujeito profissional, sendo o primeiro influenciado por sua subjetividade, cultura e aspirações pessoais, e o segundo pela constituição de valores educativos adquiridos durante sua formação.

E devido a essa complexidade é importante uma atualização constante do professor, pois é uma carreira que não se finda com a conclusão da graduação. O profissional precisa estar em constante estudo para aprimorar a sua formação.

Na sequência os supervisores avaliaram a atuação do PIBID para o conhecimento e desenvolvimento dos discentes da educação básica. As respostas obtidas foram sistematizadas no Quadro 10.

Quadro 10 - Avaliando a atuação do PIBID no desenvolvimento dos educandos

\begin{tabular}{|l|l|}
\hline Supervisores & Avaliação da atuação do PIBID \\
\hline PS-1 & $\begin{array}{l}\text { Satisfatória. Houve contribuições para o crescimento e formação } \\
\text { do estudante que aprenderam a partir de elementos do cotidiano o } \\
\text { que é Química e como essa ciência pode contribuir para o } \\
\text { encaminhamento dos nossos dilemas atuais. }\end{array}$ \\
\hline PS-2 & $\begin{array}{l}\text { Considero muito boa, o PIBID tem colaborado na resolução de } \\
\text { dificuldades, de aprendizado dos estudantes e tem nos ajudado a } \\
\text { pensar a prática dentro dessa realidade. }\end{array}$ \\
\hline PS-3 & $\begin{array}{l}\text { Engrandecedor, existe uma troca entre os estudantes, apresenta e } \\
\text { aproxima a realidade da Universidade para os estudantes da rede } \\
\text { pública. }\end{array}$ \\
\hline PS-4 & $\begin{array}{l}\text { Interativo! Uma vez que a atuação do PIBID contribui muito no } \\
\text { desenvolvimento dos alunos do Ensino médio, pois por meio do } \\
\text { programa podemos proporcionar uma relação de aproximação } \\
\text { entre etapas diferentes de ensino. }\end{array}$ \\
\hline PS-5 & $\begin{array}{l}\text { Uma relação de ensino aprendizagem com a realidade existente } \\
\text { das escolas, proporcionando oportunidades em experiências } \\
\text { trazidas de fora da escola em que o aluno está inserido. } \\
\text { Correlacionando a educação básica com a superior, trazendo aulas } \\
\text { diferenciadas lúdicas e participativas. }\end{array}$ \\
\hline
\end{tabular}

Fonte: Dados da pesquisa

Analisando as respostas dos supervisores, dois temas foram mais citados pelos participantes do estudo sobre a atuação do PIBID para o conhecimento e desenvolvimento dos alunos do Ensino Médio. O primeiro foi a aproximação entre a escola e universidade (PS-3, PS-4 e PS-5), proporcionando uma interação entre ambos níveis de ensino com troca de 
vivências e experiências, ou seja, na construção de saberes como mencionado por Rosa, Mendes e Locatelli (2017, p. 105):

[...] Essa fonte de saber se consolida ao tecer relações com os saberes advindos da Universidade, das leituras e pesquisas realizadas sobre os processos educativos e na interação entre bolsistas de iniciação à docência, professores coordenadores de área e os professores supervisores das escolas de Educação Básica.

Essa relação escola-universidade é muito importante para o desenvolvimento de trabalhos colaborativos que refletem na realidade escolar. E o segundo tema sinalizado pelos sujeitos participantes deste estudo foi referente a essa contribuição do programa com a aprendizagem do aluno (PS1, PS-2, PS-4 e PS-5), pois os pibidianos ajudam na construção de aulas interativas e diferenciadas (PS-2 e PS-5), colaborando com a resolução de dificuldades de aprendizagem (PS-2) e tornando o conteúdo químico mais próximo da realidade do aluno, contextualizando o ensino de Química. (PS-1 e PS-5). Amaral (2012, p. 229, grifos nossos) destacou esse fato no seu trabalho:

[...] o programa cria oportunidades de formação em exercício para os professores da escola, quando estes participam no planejamento de ações, juntamente com professores da universidade e licenciandos, a partir da reflexão e discussão sobre questões de aprendizagem, ensino e contexto escolar.

Essas oportunidades criadas pelo PIBID contribuem tanto para proporcionar novas alternativas e reflexões para a aprendizagem dos conteúdos químicos, discutindo novas estratégias e recursos didáticos a serem utilizados, quanto torna a formação inicial do bolsista consistente pois há uma aproximação com o contexto escolar e com as condições do trabalho docente. Apesar dos limites sinalizados neste trabalho, e que são importantes para a reflexão de melhorias das ações e estrutura do programa, destacamos potencialidades consistentes para a continuação do PIBID nas escolas.

\section{Considerações Finais}

Essa pesquisa possibilitou maior entendimento acerca do PIBID. Em diversos estudos relacionados a esse programa percebemos dados 
consistentes e argumentos sólidos da importância para a formação inicial dos professores e ao mesmo tempo na colaboração com as escolas da educação básica. Nesta investigação direcionamos o diálogo para os professores supervisores, pedindo que avaliassem e pontuassem os limites $e$ potencialidades dos subprojetos de Química para a sua realidade escolar.

Ao findar o trabalho, percebemos que o PIBID além de proporcionar a iniciação de novos professores na docência também contribui para a formação continuada dos profissionais que atuam nas escolas. A participação dos supervisores nos subprojetos analisados nos mostrou a construção de diversos saberes importantes para a profissão docente. Ao analisarem as práticas pedagógicas construídas coletivamente com os pibidianos, esses sujeitos passaram a pensar criticamente sobre a própria ação em sala de aula. Eles também possibilitaram aos licenciandos uma visão real do contexto escolar e, por outro lado, promoveram em si mesmos uma reflexão crítica da sua atuação na sala de aula.

Não podemos deixar de destacar a importância do supervisor para a concretização do PIBID nos colégios parceiros, pois é pelo seu intermédio que as portas das escolas são abertas para a universidade. Também são importantes mediadores na formação inicial dos pibidianos, pois são profissionais mais experientes e se dispõem a abrir as suas salas de aulas e trocar informações e ideias sobre o ensino de Química, repensando a mediação de conflitos e debatendo coletivamente as dificuldades de ensino dos seus alunos.

A partir da concepção dos próprios supervisores, o PIBID alterou e/ou provocou algumas modificações na sua prática docente e também deixaram materiais que os mesmos ainda continuam utilizando nas suas aulas. Portanto, entendemos que a participação nesse programa contribui para o desenvolvimento profissional desses professores ao refletirem sobre a docência de forma coletiva. 


\section{Referências}

AMARAL, E. M. R. Avaliando contribuições para a formação docente: uma análise de atividades realizadas no PIBID-Química da UFRPE. Química Nova na escola, v. 34, n. 4, p. 229-239, 2012. Disponível em: http://qnesc.sbq.org.br/online/qnesc34_4/09-PIBID-108-12.pdf. Acesso em 2 maio 2020.

BRASIL. CAPES. Portaria N $N^{\circ} 72$, de 9 de abril de 2010. Dá nova redação a Portaria que dispõe sobre o Programa Institucional de Bolsa de Iniciação à Docência - PIBID, no âmbito da CAPES. DOU: Seção 1, Brasília, DF, ano 147, n. 68 , p. 26-27, 12 abr. 2010a. Disponível em: https://pesquisa.in.gov.br/imprensa/jsp/visualiza/index.jsp?jornal=1\&pagina=26 \&data=12/04/2010. Acesso em 5 ago. 2020.

. Decreto $N^{0} 7.219$, de 24 de junho de 2010. Dispõe sobre o Programa Institucional de Bolsa de Iniciação à Docência - PIBID e dá outras providências. DOU: Seção 1, Brasília, DF, ano147, n. 120, p. 4-5, 25 jun. 2010b. Disponível em:

https://pesquisa.in.gov.br/imprensa/jsp/visualiza/index.jsp?jornal=1\&pagina=4\& data=25/06/2010. Acesso em 5 ago. 2020.

. Conselho Nacional de Saúde. Resolução № 466, de 12 de dezembro de 2012, que aprova as diretrizes e normas regulamentadoras de pesquisas envolvendo seres humanos. DOU: Seção 1, Brasília, DF, ano 150, n. 112, p. 59-62, 13 junho 2013a. Disponível em: https://pesquisa.in.gov.br/imprensa/jsp/visualiza/index.jsp?jornal=1\&pagina=59 \&data=13/06/2013. Acesso em 4 abr. 2020.

. CAPES. Portaria No 96, de 18 de julho de 2013. Dispõe sobre a atualização das normas do Programa Institucional de Bolsa de Iniciação à Docência. DOU: Seção 1, Brasília, DF, ano 150, n. 140, p. 11-14, 23 jul. 2013b. Disponível em: https://pesquisa.in.gov.br/imprensa/jsp/visualiza/index.jsp?data=23/07/2013\&jor nal=1\&pagina=11\&totalArquivos=72. Acesso em 5 ago. 2020.

. CAPES. Portaria No 46, de 11 de abril de 2016. Aprova o Regulamento do Programa Institucional de Bolsa de Iniciação à Docência - Pibid. DOU: Seção 1, Brasília, DF, ano 153, n. 72, p. 16, 15 abr. 2016a. Disponível em: https://pesquisa.in.gov.br/imprensa/jsp/visualiza/index.jsp?jornal=1\&pagina=16 \&data=15/04/2016. Acesso em 19 ago. 2020.

Conselho Nacional de Saúde. Resolução N 510, de 07 de abril de 2016, que dispõe sobre as normas aplicáveis a pesquisas em Ciências Humanas e Sociais. DOU: Brasília, DF, ano 153, n. 98, 24 maio 2016b, Seção 1, p. 44-46. Disponível em: https://pesquisa.in.gov.br/imprensa/jsp/visualiza/index.jsp?jornal=1\&pagina=44 \&data=24/05/2016. Acesso em 4 abr. 2020. 
MEC. INSTITUTO NACIONAL DE ESTUDOS E PESQUISAS EDUCACIONAIS ANISIO TEIXEIRA. Censo Escolar 2017: Notas Estatísticas. Brasília, DF: INEP, 2018. Disponível em: http://download.inep.gov.br/educacao_basica/censo_escolar/notas_estatisticas/ 2018/notas_estatisticas_Censo_Escolar_2017.pdf. Acesso em 25 jun. 2020.

Disponível

Censo Escolar 2018: Notas Estatísticas. Brasília, DF: INEP, 2019. http://download.inep.gov.br/educacao_basica/censo_escolar/notas_estatisticas/ 2018/notas_estatisticas_censo_escolar_2018.pdf. Ačesso em 25 jun. 2020.

CALIL, A. M. G. C. O desenvolvimento profissional dos professores Supervisores do PIBID. Revista Cocar, v. 8, n.15, p. 08-15, 2014. Disponível em: https://periodicos.uepa.br/index.php/cocar/article/view/329. Acesso em 2 abr. 2020.

CANDAU, V. M. F. A formação de educadores: uma perspectiva multidimensional. Em Aberto, v. 1, n. 8, p. 19-21, 1982. Disponível em: http://rbepold.inep.gov.br/index.php/emaberto/article/view/1393/1367. Acesso em: 1 ago. 2020.

FLECK, J. R.; SANTOS, E. G. A contribuição do PIBID na formação inicial de professores: As produções acadêmicas dos estudantes do Curso de Pedagogia do Centro Universitário Franciscano. InterEspaço, v. 2, n. 7, p. 241-261, 2016. Disponível em: http://www.periodicoseletronicos.ufma.br/index.php/interespaco/article/view/737 9. Acesso em 1 abr. 2020.

FREIRE, P. Pedagogia da Autonomia: Saberes necessários à prática educativa. São Paulo: Paz e Terra, 1996.

GATTI, B. A. et al. Professores do Brasil: novos cenários de formação. Brasília: UNESCO, 2019. Disponível em: https://www.fcc.org.br/fcc/wpcontent/uploads/2019/05/Livro ProfessoresDoBrasil.pdf. Acesso em: 3 ago. 2020.

MORAES, R; GALIAZZI, M. C. Análise textual discursiva: processo reconstrutivo de múltiplas faces. Ciência \& Educação, v. 12, n. 1, p. 117-128, 2006. Disponível em: https://www.scielo.br/pdf/ciedu/v12n1/08.pdf. Acesso em: 2 fev. 2020.

MORAES, R. Uma tempestade de luz: a compreensão possibilitada pela análise textual discursiva. Ciência \& Educação, v. 9, n. 2, p. 191-211, 2003. Disponível em: https://www.scielo.br/pdf/ciedu/v9n2/04.pdf. Acesso em: 2 fev. 2020.

OLIVEIRA L.; JUSTINA, L. A. D. O papel dos professores supervisores no PIBID de acordo com o relatado em pesquisas brasileiras. Revista Atlante, 2017. Disponível em: https://www.eumed.net/rev/atlante/2017/02/pibid.html. Acesso em 4 abr. 2020. 
PRODANOV, C. C.; FREITAS, E. C. Metodologia do Trabalho Científico: Métodos e Técnicas da Pesquisa e do Trabalho Acadêmico. 2. ed. Nova Hamburgo-RS: FEEVALE, 2013.

ROSA, D. L.; MENDES, A. N. F.; LOCATELLI, A. B. Perspectivas epistemológicas na formação inicial de professores para o ensino de Química através das ações docentes dos bolsistas PIBID/CEUNES/UFES. Kiri-Kerê, n. 3, p. 97-112, 2017. Disponível em: https://periodicos.ufes.br/index.php/kirikere/article/view/17134. Acesso em: 2 mar. 2020.

ROSA, K. S.; MATTOS, L. Tem gente nova na escola: os benefícios do Pibid para o espaço escolar. Revista Veras, v. 3, n. 2, p. 160-173, 2013. Disponível em:

https://site.veracruz.edu.br/instituto/revistaveras/index.php/revistaveras/article/vi ew/130. Acesso em: 4 maio 2020.

TOZONI-REIS, M. F. C. Metodologia da Pesquisa. 2. ed. Curitiba: IESDE, 2009.

VOGEL, M.; ABREU, R. C. A formação docente e as narrativas (auto)biográficas: um diálogo com um licenciando em Química participante do PIBID. Kiri-kerê, n. 7, p. 9-38, 2019. Disponível em: https://periodicos.ufes.br/kirikere/article/view/25924. Acesso em 2 mar. 2020.

\section{Sobre os autores}

\section{Lucas dos Santos Galiza}

lucasgaliza15@gmail.com

Graduando em Química pelo centro de formação de professores da Universidade Federal do Recôncavo da Bahia (CFP-UFRB) e Técnico em Agropecuária formado no Instituto Federal de Educação, Ciência e Tecnologia Baiano - Campus Santa Inês. Membro do grupo de pesquisa DOCFORMGrupo de Pesquisa em Docência, Currículo e Formação/UFRB.

\section{José Gilberto da Silva}

gilberto@ufrb.edu.br

Doutor em Química pela Universidade Federal de Minas Gerais (UFMG). Pósdoutorado pela UFMG; Professor Associado do curso de Licenciatura em Química do Centro de Formação de Professores (CFP) da Universidade Federal do Recôncavo da Bahia (UFRB); Membro do grupo de pesquisa DOCFORM- Grupo de Pesquisa em Docência, Currículo e Formação/UFRB.

\section{Mara A. Alves da Silva}

mara@ufrb.edu.br

Doutoranda em Educação pela Universidade Federal da Bahia (UFBA); Mestre em Ensino de Ciências e Matemática pela Universidade Estadual do Sudoeste da Bahia (UESB); Professora Assistente do curso de Licenciatura em Química 
do Centro de Formação de Professores (CFP) da Universidade Federal do Recôncavo da Bahia (UFRB); Estuda no Programa de Pós-Graduação em Educação na Faculdade de Educação (FACED) da UFBA; Membro do grupo de pesquisa DOCFORM- Grupo de Pesquisa em Docência, Currículo e Formação/UFRB. 